\title{
FUNCTIONAL WRITING IN CANADA: AN OVERVIEW OF CAREER OPPORTUMITIES*
}

\author{
Jennifer J. Connor
}

As teachers of functional writing, we need current information about developments in the field and the needs of its practitioners. While recent surveys do indicate trends, they deal mainly with the teaching of the subject or with types of, writing required by some occupational groups in the United States. 1 In addition to these studies, Canadians in particular need information about the rapidly growing number of people employed here full time in writing or editing activities. One way to gather information is by examining employer requirements for writing positions as they are reflected in published career opportunities. While such an approach does have limitations because it deals with perceptions of terminology and position titles, which may be misleading, it nevertheless should provide some insights into the current state of the field and suggest implications for both practitioners and instructors.

In this paper, then, I will examine positions advertised in Canada over the last three years (from August 1983 to May 1986), including those for general editors, public relations writers, organizational communicators, translators, and technical writers. Main sources for this survey include major newspapers (the Globe and Mail, and the Toronto Star), as well as the bulletin of the Society for Technical Communication (Toronto Chapter).

Direct comparison according to all criteria (experience, qualifications, salary, etc.) is not possible, since advertisements are not in standardized form. However, as I am mainly interested in determining trends and, to a certain extent, employer perceptions of the field, the advertisements provide pertinent information for this discussion.

In all, 260 advertisements were collected during this period, including those for short-term contract positions. The number of positions is sufficient to indicate any trends, although the survey is not exhaustive. Since the field tends to divide naturally into two main areas, corporate and editorial work, and technical writing, I discuss them separately.

\section{Corporate and Editorial Positions}

This category accounted for 100 positions, or $39 \%$ of all positions advertised. However, unlike the technical writing positions which constituted the bulk of the advertisements $(61 \%)$, as Table 1 shows, this category represents career opportunities in four separate areas. 
Table 1

\section{DISTRIBUTION OF \\ CORPORATE AND EDITORIAL POSITIUNS}

Position

Editing

Organizational Communications

Public Relations

Translating
Percentage

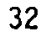

26

24

18

100

Generally, advertisements stressed experience--usually a minimum of three years--over educational qualifications for these positions. Moreover, when they did mention degrees, the organizations advertising looked primarily for journalism graduates. This was especially so for pubiic relations positions, where familiarity with the media was often cited as desirable. In addition, public relations writers were often required to prepare information using a variety of print and non-print media, including displays for trade shows and audio-visual materials. Their writing by and large is for an external audience (via brochures, news releases, etc.); organizational communicators, on the other hand, tend to write for other employees (policy and procedure manuals, in-house newsletters, etc.). Position titles for corporate positions varied, often widely; for example, a "Public Relations officer" and "Communications Co-Ordinator" essentially might perform the same job for different organizations. In contrast, editing position titles were more consistent: the position of "Editor" was advertised for various associations and general publishers.

Few advertisements for corporate and editing positions indicated a salary, but of those that did, the range was from $\$ 17 \mathrm{~K}$ for a private association to $\$ 47 \mathrm{~K}$ for a government position in public relations.

Roughiy $18 \%$ of the corporate writing positions were actually in translating, mainly for government and financial institutions. All but one were English/French positions (or vice versa); the exception was a position involving Japanese/English translating for a Japanese car manufacturer. Duties for translators involved mainly editing and translating company publications, legal contracts and some technical material. Indeed, two companies advertised specifically for a Technical Translator (Traducteur Technique). Both a degree or diplona in translation and 3-5 years' experience were required for all the English/French translator positions.

\section{Technical Writing}

of the 260 positions advertised, this category alone accounted for 
$160(61 \%)$, including 10 "Technical Illustrator/Writer" positions. Basically, technical illustrator openings were in industry and usually involved engineering or line drawing for service or operator manuals; qualifications of a three-year programme in technical illustration and 2-5 years' experience were mentioned.

The position title "Technical Writer" appeared consistently in the advertisements (unlike the variety of titles advertised in corporate communications); and, as Table 2 shows, technical writers had a choice of industries in which they might work, the overwhelming majority of them in the computers/electronics field.

\section{Table 2}

TECHNICAL WRITING PUSITIONS BY INDUSTRY

Industry

Computers/Electronics

General Manufacturing

Aerospace

Government, consulting, mi scellaneous

Mining/Petroleum

Financial

\section{Percentage}

71

11

10

4

3

1

100

In general, the duties for "Technical Writer" consistently called for writing, with some editing, pasteup and proofreading. Some advertisements also mentioned testing (i.e., software) and training or teaching as additional activities. A large number of advertisements (43\%) specifically referred to manuals as the type of writing required; moreover, many outlined the types of manuals to be prepared: operator or user, service or maintenance, or policy and procedure. ${ }^{2}$ Other types of writing frequently cited were specifications and a variety of assignments including technical bulletins, articles, reports and brochures. At least three organizations requested candidates give samples of their work.

Organizations which required degrees for technical writers sought a wider range of disciplines than those required for corporate positions; in particular, most required postsecondary education in science or engineering, sometimes indicating a specific science or branch of engineering (e.g., electrical engineering). This emphasis on technical qualifications is underscored by the fact that many advertisements for technical writers appeared under the headings "Engineers" or "Engineering Opportunities." While other advertisements did not specify a discipline, a technical degree seemed implicit for the position advertised 
since they often emphasized a background in computer science; and finally, only a few mentioned humanities degrees, notably English, or professional degrees such as journalism. Only two advertisements--both in 1986--called for a "completed technical writing course" or a "Technical Communication course."

In addition to qualifications and writing ability, advertisements frequently listed skills and knowledge in other areas: illustrating, graphics, drawings or blueprints; on-line text editing; and military specifications (which were especially important for positions in the aerospace industry). Some identified computer languages, such as BASIC or FORTRAN, with which the writer must be familiar.

Organizations usually required 3-5 years' experience for a technical writer, or 7-10 years for a managerial position such as "Technical Publications Supervisor". Many sought practical engineering experience as well.

An annual salary figure appeared more often in the advertisements for technical writers, the most frequent being $\$ 30 \mathrm{~K}$ with a range of $\$ 25 \mathrm{~K}$ for a technical writer to $\$ 60 \mathrm{~K}$ for a senior technical writer (one in the military). 3 Contractual positions, those offering a few months' work to complete a specific project, generally advertised an hourly rate of $\$ 25-35$.

Finally, as Table 3 shows, the majority of positions were in Ontario, with the Toronto region accounting for almost all of these. 4 This skewed situation partly arises from the fact that the newspapers surveyed originate from Toronto. (The papers do, however, have national circulations.) The table does not include five cities (three in Ontario) with one advertisement each for technical writers, and it does not total 160 positions since not all advertisements indicated the place of employment.

\section{Table 3}

GEOGRAPHIC DISTRIBUTION OF TECHNICAL WRITING POSITIONS

\section{By province:}

\begin{tabular}{lr} 
Ontario & 119 \\
Western provinces & 11 \\
Quebec & 6 \\
Maritimes & 1 \\
& \\
By city: & \\
\hline & \\
Toronto and region & 110 \\
Calgary & 7 \\
Montreal & 6 \\
Ottawa & 4 \\
Kingston & 2 \\
Edmonton & 2
\end{tabular}




\section{General Observations}

This survey of 260 career opportunities indicates a few trends in functional or professional writing in Canada, particularly with respect to technical writing.

1. Few, if any, advertisements were for entry-level positions: most positions required a minimum of 3 years' experience. Related to this point is the repeat advertisement: in several instances companies advertised again for what appeared to be the same position of technical writer (these were not included in the survey count). While repeat advertisements may indicate more positions than technical writers to fill them, they may also indicate a high turnover in some positions. Turnover may result from promotions within the organization or from career moves (for example, from technical writer to senior technical writer or manager). ${ }^{5}$ In either case, apparently the opportunities for technical writers are expanding and developing in Canada.

2. In industry, educational qualifications for the two main categories of professional writing--corporate and editorial, and technical writing--clearly differ. For corporate writing a degree in journalism is most appropriate, while for technical writing a degree in engineering or computer science is important. Employers 'understanding of the title "technical writer," then, definitely places emphasis on the "technical", not on the "writing." 6

3. Skills in addition to writing are important for both types of positions. For the corporate and editing positions (especially public relations), knowledge of non-print media is important, and for technical writing positions knowledge of illustrating and training experience is often required.

4. In both areas, especially technical writing, manuals were commonly mentioned as the main form of writing.

\section{Implications for Technical Writers and Instructors}

The significance of this brief survey lies in the fact that of all the different professional writing opportunities in Canada over the past three years, technical writing positions represent the largest single group. Not only were there more openings for technical writers than for any other type of writing position, but those openings indicate that employers see a need for specialized training and education in the sciences. Candidates for these positions (as distinct from technical editors), then, should probably prepare for them by studying computer science and/or engineering; they might also consider a technical writing course to enhance their chances for employment. 
Moreover, even if they do not know now what their career path might be, candidates with a background in science will perhaps be better prepared for future career moves within an organization (i.e., from technical positions to technical writing positions). Indeed, in Canada it would appear that internal career moves are the norm since no opportunities were advertised for entry-level positions (although some employers may now be hiring directly from postsecondary campuses as they learn of the newly instituted programmes).

Such specialized requirements, set by employers for technical writers, have implications for teaching technical writing as well. As technical writing instructors, we should make sure we expose students to graphics and illustrating in conjunction with topics in writing. For most instructors, perhaps, this will mean using computers in the classroom for purposes other than word processing; furthermore, depending on instructors' backgrounds (which are often in the humanities), it may also become imperative to develop a co-operative approach to teaching technical writing with technical faculty. ${ }^{2}$ Course coverage of these topics will help prepare students for positions as technical writers, or indeed for work in technical editing where familiarity with technical illustration would also be an asset.

In addition, since technical writers often train others, intructors should continue to teach oral presentation skills, and preparing information for different modes of presentation. Although some might argue that oral presentations have no place in a writing course, clearly fulltime technical writers would benefit from such instruction. Perhaps instructors could consider developing broader courses in "Technica: Communication" to incorporate other facets of the technical writer's job, including oral communication, 8 editing, and organizational communication.

Finally, instructors should perhaps place more emphasis on teaching preparation of manuals, especially in courses which are part of a technical writing programme. While this recommendation admittedly is problematic for a single already-busy course in technical writing, instructors could attempt to integrate the components of technical writing (description, definition, specifications, etc.) within the context of a completed project: the manual. This approach might include, for instance, briefly discussing the preparation of manuals, including page layout, indexing, pagination, updating, printing and binding hard copy, production techniques in general, and manuals control. In a larger course, perhaps different writing assignments on a single topic can evolve into students' production of a short manual by the end of the course. If nothing else, the process should ensure students do not think of assignments as isolated writing events.

Technical writing courses which take into account these implications would not only better prepare students for the type of writing they may encounter in their careers, but they may also prepare them for careers in technical writing. Moreover, as Canadian employers become more aware of such courses and hire graduates from the new Canadian 
programmes, they may modify their requirements for technical writing positions. A follow-up survey of employers themselves in five or ten years would indicate any such developments at that time.

\section{NOTES}

*An earlier version of this paper was presented at the annual conference of the Canadian Association of Teachers of Technical Writing at the University of Manitoba, May 28-29, 1986.

1. For Canadian surveys of teaching, see Ron S. Blicq, "The Teacher of Technical Writing in Canada: A Profile," Technostyle 4(Spring 1985): 1-19; and E. Rennie Charles, "The Teaching of Business Communication in Canada," in Herbert W. Hildebrandt, ed., International Business Communication: Theory, Practice, Teaching Throughout the World (Ann Arbor: University of Michigan, 1981), pp. 117-31.

For American surveys of specific occupations see, for example, Thomas E. Harris and Jennings Bryant, "The Corporate Communication Manager," Journal of Business Communication 23 (Summer 1986):19-29; James C. Bennett and Robert J. OTney, "Executive Priorities for Effective Communication in an Information Society," Journal of Business Communication 23(Spring 1986):13-22; Frank C. Cronin, "Writing Requirements in a Large Construction Firm," Technical Writing Teacher 10(Winter 1983):81-85; C. Gilbert storms, "What Business School Graduates Say About the Writing They Do at Work: Implications for the Business Communication Course," ABCA Bulletin 46(December 1983):13-18.

2. The service manual has also been identified as the main form of writing for the aeronautics technical writer in Canada; see Reynolds Kanary and Carolynn Emeyriat, "Profile of an Aeronautics Technical Writer," Technostyle 5(Spring 1986):50-51.

3. This figure also corresponds to the average salary of technical writers in Toronto, according to a recent survey by the Toronto Chapter of the Society for Technical Communication. See Communication Times 14(April 1986):4-5.

4. According to another survey, approximately 87 positions a year are advertised in the Toronto area: Candace Séguinot, "Developing a Technical Writing Programme," paper presented at the annual conference of the Canadian Association of Teachers of Technical Writing, University of Manitoba, May 28, 1986.

5. For a discussion of career inoves see Michael Burke, "Career Opportunities in Computer Documentation," Technical Communication 33(First Quarter 1986):13-15. 
6. This emphasis may not reflect positions which, although entitled "Technical Writer", involve technical editing. These positions usually require the ability to determine appropriateness of "technical" text based on knowledge of the intended audience's needs. Thus, technical editing--a growing specialty, but one which is not widely advertised-requires a sound knowledge of the language and logical presentation of information.

7. For discussions of co-operative approaches, see Nancy Roundy, "Team-Teaching Technical Writing: Audience Analysis and the Lab Report," Engineering Education 72(February 1982):395-96; M.T. (Jean) Dohaney, "A Cumulative and Co-operative Approach to Writing Development in a Forestry Faculty," Technostyle 3(Spring 1984):6-8; and Charles H. Sides, "The MIT Technical Writing Cooperative," Technical Writing Teacher 13(Spring 1986):118-20.

8. For suggestions on including oral communication in technical writing courses, see Janet $H$. Potvin, "The Simulated Professional Meeting: A Context for Teaching Oral Presentation in the Technical Communication Course," Journal of Technical Writing and Communication 14(1984): 59-68; Judith L. Stephens and Arthur J. Marsicano, "Adapting the Basic Speech Communication Course for Engineering and Engineering Technology Majors," Journal of Technical Writing and Communication 14(1984):133-42.

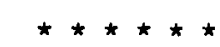

Jennifer J. Connor holds an M.Phil. in English. She has experience as a technical writer, editing policy/procedure manuals for a trust company, and as a project director/writer, preparing a reference work on urban demography for social service agencies. Currently she teaches communication courses in the Centre for Administrative and Information Studies, University of Western Ontario. 